\title{
Customer Satisfaction Assessment at the Pacific Northwest National Laboratory
}

D. N. Anderson

M. L. Sours

March 2000

Prepared for

the U.S. Department of Energy

under Contract DE-AC06-76RLO 1830

Pacific Northwest National Laboratory

Richland, Washington 99352 


\section{DISCLAIMER}

This report was. prepared as an account of work sponsored by an agency of the United States Government. Neither the United States Government nor any agency thereof, nor any of their employees, make any warranty, express or implied, or assumes any legal liability or responsibility for the accuracy, completeness, or usefulness of any information, apparatus, product, or process disclosed, or represents that its use would not infringe privately owned rights. Reference herein to any specific commercial product, process, or service by trade name, trademark, manufacturer, or otherwise does not necessarily constitute or imply its endorsement, recommendation, or favoring by the United States Government or any agency thereof. The views and opinions of authors expressed herein do not necessarily state or reflect those of the United States Government or any agency thereof. 


\section{DISCLAIMER}

Portions of this document may be illegible in electronic image products. Images are produced from the best available original document. 


\section{Abstract}

The Pacific Northwest National Laboratory (PNNL) is developing and implementing a customer satisfaction assessment program (CSAP) to assess the quality of research and development provided by the laboratory. This report presents the customer survey component of the PNNL CSAP. The customer survey questionnaire is composed of two major sections: Strategic Value and Project Performance. Both sections contain a set of questions that can be answered with a 5-point Likert scale response. The Strategic Value section consists of five questions that are designed to determine if a project directly contributes to critical future national needs. The Project Performance section consists of nine questions designed to determine PNNL performance in meeting customer expectations. A statistical model for customer survey data is developed and this report discusses how to analyze the data with this model. The properties of the statistical model can be used to establish a "gold standard" or performance expectation for the laboratory, and then to assess progress. The gold standard is defined using laboratory management input answers to four questions, in terms of the information obtained from the customer survey:

1. What should the average Strategic Value be for the laboratory project portfolio?

2. What Strategic Value interval should include most of the projects in the laboratory portfolio?

3. What should average Project Performance be for projects with a Strategic Value of about 2 ?

4. What should average Project Performance be for projects with a Strategic Value of about 4 ?

To be able to provide meaningful answers to these questions, the PNNL customer survey will need to be fully implemented for several years, thus providing a link between management perceptions of laboratory performance and customer survey data: 


\section{Introduction}

The Pacific Northwest National Laboratory (PNNL) is a multi-program laboratory operated by Battelle for the United States Department of Energy (DOE). PNNL is one of the laboratories operated by the DOE Office of Science. PNNL is tasked with the development and delivery of technology in environmental science, energy science, health science and national security. The laboratory employs approximately 3500 staff members and has an operating budget of approximately $\$ 500$ to $\$ 600$ million. Battelle strives to operate the laboratory in the most efficient and effective manner possible and to provide customers with innovative technical solutions to their most strategic problems. Customer feedback is a critical factor in identifying improvements necessary to meet these goals. This paper presents the customer survey component of laboratory customer satisfaction assessment program (CSAP). Compelling arguments in support of customer satisfaction surveys can be found in [Kessler, 1995], [Vavra, 1996], [Kessler, 1996] and [Hayes, 1998].

Section 2 is an overview of the customer survey process. Section 3 discusses the analysis of customer survey data, including a statistical model of the data that can be used to annually assess customer satisfaction. Section 4 concludes with some important implementation issues. The mathematical and statistical details are in Appendix A, and a copy of the questionnaire is shown in Appendix B.

\section{PNNL Customer Satisfaction Survey}

In general, laboratory performance information is gathered informally from customers. This informal communication provides PNNL managers with opportunities to immediately act on customer needs and is an invaluable component of any CSAP. However, it does not provide a quantitative, impartial process for collecting a broad spectrum of feedback. A formal customer satisfaction survey can be analyzed to detect shifts in performance. This analysis can initiate laboratory level improvement decisions. The customer satisfaction questionnaire developed at PNNL asks customers to assess laboratory performance in the areas of technical creativity, cost effectiveness, staff responsiveness, technical teaming, technical experience and maturity, staff satisfaction with the work environment, national and financial impact laboratory products, visibility of laboratory products, and strategic national value of laboratory products.

A customer survey can drive some important and positive changes in business operations. A properly implemented CSAP imposes uniform staff accountability for the quality of laboratory products. This can be a marked change in day-to-day operations. A CSAP clarifies staff roles and responsibilities, and can completely redefine staff performance expectations. In terms of a customer survey, these impacts are a result of expressed opinions from customers on how they want "their" laboratory managed. 
The core of the customer survey is a statistical analysis of customer answers provided on questionnaires. The questionnaire reproduced in Appendix B is composed of two major sections, Strategic Value and Project Performance. The Strategic Value section consists of five questions that can be answered with a 5-point Likert scale response. The Project Performance section consists of nine questions that can be answered with a 5-point likert scale response. The questionnaire also asks the customer to comment on issues that may not be represented in these sections. For each returned questionnaire, an average of the Likert responses is computed for both major sections. These averages are termed the Strategic Value and the Project Performance composite scores.

At PNNL, the quality of proposed and funded work is managed and maintained by business unit managers. For each business unit, a number of projects are selected randomly each year from a list of active projects. Prior to the survey, business unit managers review the projects for which they are responsible and give a Strategic Value composite score for each project. This exercise determines, in the opinion of business unit managers, which projects are aligned with strategic national needs. Projects with low Strategic Value may include work at the end of important national initiatives or important short-term work. This activity does not imply that some projects are not important. Rather, it determines if the laboratory is strategically positioned to contribute to future national initiatives. The information from this exercise can be compared visually with customer assessment of Strategic Value. Significant discordance may or may not indicate a need to redirect marketing and capability development funds. This analysis is discussed further in Section 3.

The statistical model is easily interpreted, is versatile, and effectively contributes to decisions. The Strategic Value composite is modeled with a $\beta$ distribution. The Project Performance composite is a simple linear regression on Strategic Value, embedded into a $\beta$ distribution - Project Performance $=\lambda+\rho$ Strategic Value. The $\beta$ distribution models the fact that Likert composites are bounded (in the interval 1 to 5) and it also can capture various degrees of skewness in the data. A formal mathematical description of this model is provided in Appendix A. Example plots of the model follow in Section 3.

The composite scores are used to analyze general laboratory performance and determine the relationship between Strategic Value and Project Performance. The statistical model provides the framework to determine if Project Performance is unduly influenced by Strategic Value and to assess whether the data are consistent with laboratory performance expectations. The properties of the statistical model can be used to establish a gold standard or expectation for laboratory performance, and then assess progress. The gold standard is defined by input from laboratory management. The model is designed with structure that lends itself to easy interpretation. Linking model structure directly to understandable descriptions (or attributes) of Strategic Value and Project Performance is the key to defining a gold standard model. As an example, a pilot survey of customer satisfaction could provide answers to the following questions:

1. What should the average Strategic Value be for the laboratory project portfolio? - 


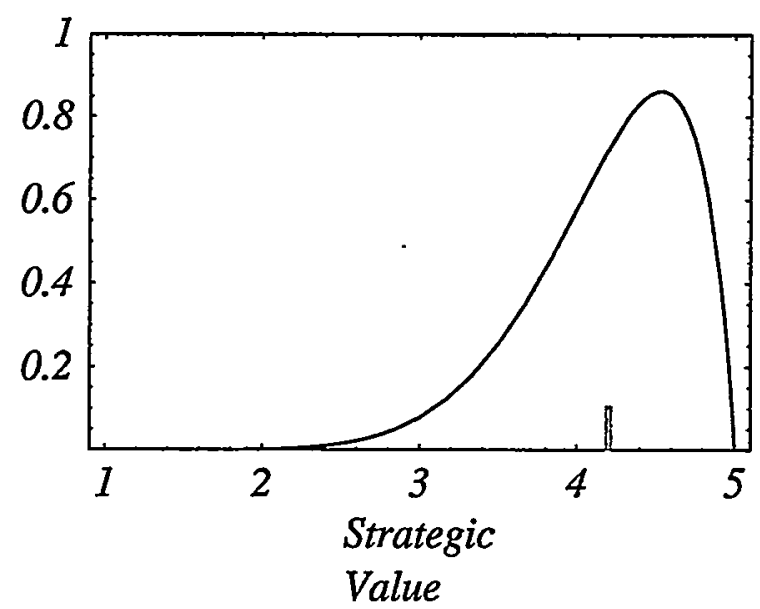

Figure 1: Strategic Value Distribution of Laboratory Portfolio.

\section{2}

2. What Strategic Value interval should include most of the projects in the laboratory portfolio? -3 to 5

3. What should average Project Performance be for projects with a Strategic Value of about $2 ?-4$

4. What should average Project Performance be for projects with a Strategic Value of about $4 ?-4.3$

A plot of the gold standard model serves as a final check of tenability. The plots for this example are displayed in Figures 1 and 2. These plots are constructed from Equations 1 and 2 in Appendix A.

In summary, the customer survey analysis is composed of an easily interpreted composite score model, the development of a gold standard model (a laboratory expectation), an analysis of the agreement between customer and PNNL manager assessments of Strategic Value, and statistical methods to analyze survey data with the composite score model. Section 3 demonstrates that customer satisfaction assessment can be based on a "process . control" philosophy. This approach is the proper analysis strategy. The gold standard model effectively defines a lower control limit (LCL) for project performance. With this LCL, the laboratory is able to objectively identify projects that need extra attention and to avoid unnecessary disruptions in projects that are meeting or exceeding customer expectations. An improvement action plan, grounded on respect for technical staff, management and customer, can be a welcome catalyst to improve performance. Such plans often facilitate a dialogue that helps raise performance levels. 

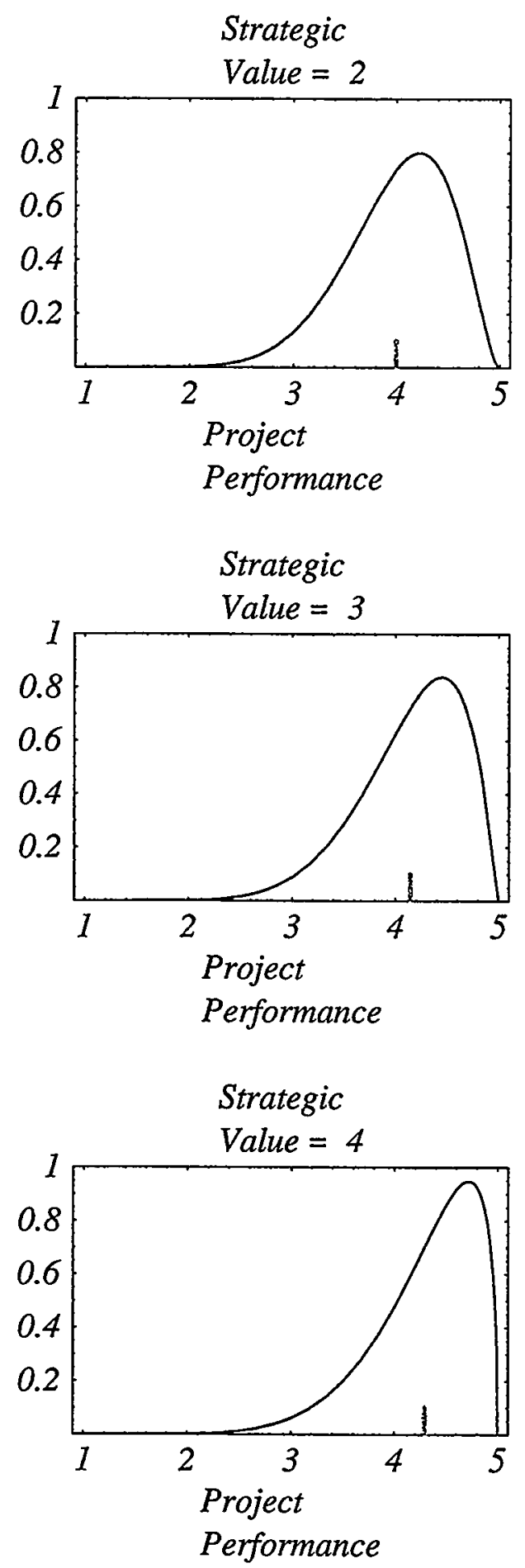

Figure 2: Project Performance Distribution for Projects with a Given Strategic Value. 


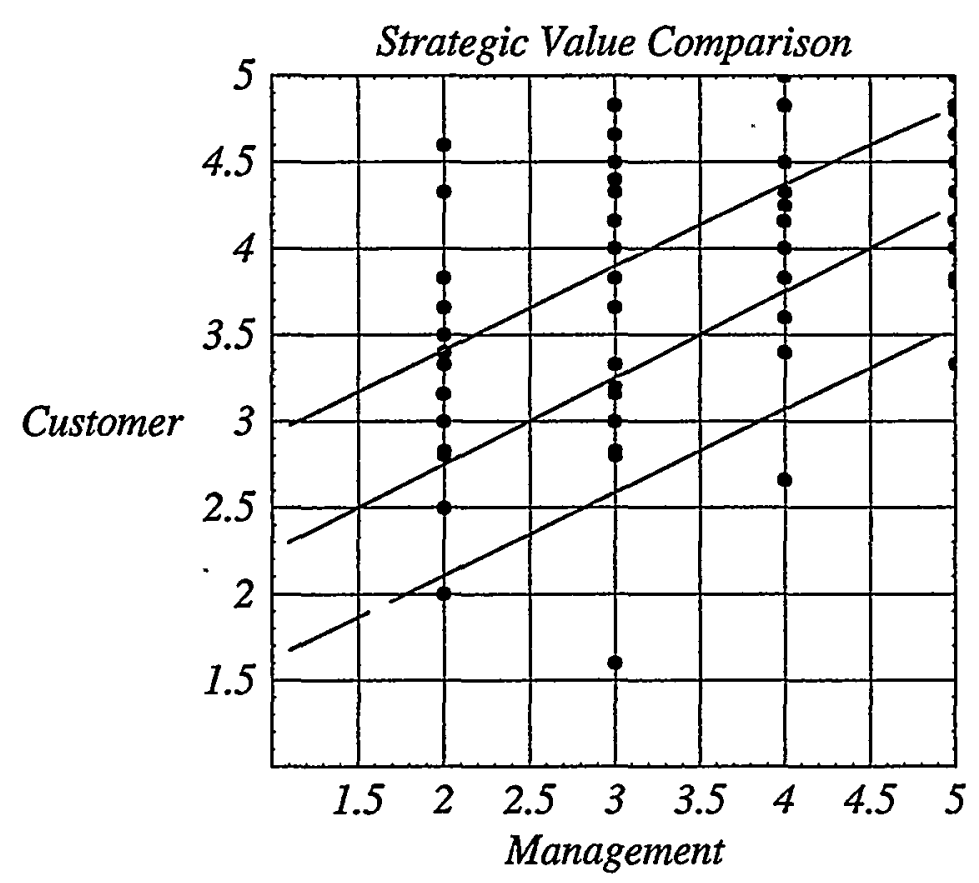

Figure 3: Example scatter plot of customer and PNNL manager assessments of Strategic Value. The black line is one possible strong concordance line. The red lines form a $90 \%$ probability region.

However, even the best of improvement action plans can be improperly applied. Many projects have the staff and solid customer relationship to independently step up to customer expectations. An improvement action plan directed at these projects may actually disrupt good customer relations and undermine staff morale. An objective method for identifying projects that need extra attention is cost effective and healthy for the morale of the laboratory.

\section{Data Analysis Strategies}

The questionnaires are distributed, according to a statistical survey design, to a random sample of projects. A random sample protects the analysis from real and perceived bias. Also, a random sample ensures that resources are available for tasks that will ameliorate non-response. A high response rate will yield impartial and defensible information. A good practical resource for statistical survey methods is [Scheaffer et al., 1990]. 


\subsection{Agreement Between Customer and PNNL Business Unit Manager Assessments of Strategic Value}

For each returned questionnaire, the composite scores (average of the Likert responses) are computed from the Strategic Value and Project Performance questions. The first analysis studies the agreement between customer and PNNL manager assessments of Strategic Value. As noted in Section 2, PNNL managers independently review the projects they are responsible for, and assign a Strategic Value score to each of these projects. Let $x_{1}, x_{2}, \ldots, x_{n}$ be the Strategic Value composites from the questionnaires (customers) and let $x_{1}^{\prime}, x_{2}^{\prime}, \ldots, x_{n}^{\prime}$ be the PNNL manager composites. The intent is an analysis that will determine if there is agreement between the paired Strategic Value composites $x_{i}$ and $x_{i}^{\prime}$. A simple scatter plot of $x_{i}^{\prime}$ versus $x_{i}$ can be used as catalyst for this analysis. Strong agreement between customer and PNNL manager assessments of Strategic Value will be evident in a scatter plot with points clustered around a near 45 degree line (slope less than one). Appendix A provides the statistical framework to construct a comparison line and region, and the statistical reasons showing the slope of a comparison line must be less than one. An example scatter plot, comparison line, and region is given in Figure 3.

A conclusion that leans toward Strategic Value discordance may not be cause for radical changes in marketing and capability development funds. PNNL managers may have information beyond the scope of the questionnaire that would lead them to continue to support certain business strategies. For example, PNNL managers may be key contributors to strategic national research agendas, and in that capacity have a comprehensive understanding of strategic national needs. This analysis serves two important functions. First, it can be used to assess whether laboratory management and customers agree on the strategic relevance of funded work at PNNL. Second, it can be used as evidence to motivate a redirection of laboratory marketing and capability development funds.

\subsection{Agreement Between the Survey Data and the Gold Standard}

Answers to the four questions discussed in Section 2 define the laboratory gold standard. A simple statistical method can be constructed to determine if annual survey data are consistent with this standard. Concepts from statistical process control techniques are used to perform this analysis. Technical details and important assumptions about this procedure are given in Appendix A. The analysis method presented in this section will simultaneously test for the compliance of average Project Performance and Project Performance variability. As discussed in Section 2, the Project Performance composite is modeled as a simple linear regression on Strategic Value. This model provides the ability to define a $p$ th percentile line, similar to the line Project Performance $=\lambda+\rho$ Strategic Value. If the gold standard model is a tenable representation of laboratory performance, no more than about $p \%$ of the data will be below this line. A statistically large number of points below this line indicate disagreement with the gold standard model. The PNNL assessment procedure involves ascribing adjectives to a count of the number of points below the LCL. 
Figure 4 illustrates these rating regions. For example, if no more than 6 out of 75 questionnaires have composite scores below the $5^{\text {th }}$ percentile line $(p=5)$, a rating of Outstanding would be given. In Figure 4, the cross lines of the gold standard model represent an average target for Project Performance and Strategic Value, the gray line is Project Performance $=\lambda+\rho$ Strategic Value, and the gold line is the $5^{\text {th }}$ percentile line. For the ratings figure, the gray region is described as Marginal/Poor, the red region is described as Good, the blue region is described as Excellent, and the green region is described as Outstanding.

\section{Implementation Issues and Conclusions}

By expanding the methods of listening to customers, the laboratory can gain an understanding of improvements it can implement to better serve its customers. As with any business, the verbal feedback received from customers is at risk of being lost in the organization. With a survey tool, the laboratory is able to process the information and quantitatively pinpoint opportunities for improvement. Also, organizational learning and strategic decisions are grounded in defensible data analysis. As a result of the CSAP program, the culture of the laboratory will become keenly focused on customer satisfaction. By capturing the valuable feedback the customer is providing about performance, management can look for ways to improve efficiency of operations, service, and product quality. As a result PNNL can optimize its stewardship of government monies dedicated to national scientific research and development. Some important implementation issues follow.

PNNL has a complex client base and feedback is needed from all segments of this client base. Funding clients have different perspectives than technical or contracting clients, and all feedback provides opportunity for improvements. If an adequate customer database does not exist, a customer survey can be labor intensive. The database must be linked to financial information and to internal project contacts such as project managers and relationship managers.

The response rate should be high when collecting feedback from customers. Customers are not cold-canvas contacts as in surveys where a $40 \%$ response rate is viewed as near optimal. These individuals, in some instances, are entrusting PNNL with millions of dollars to complete needed research and development. All projects in the laboratory portfolio are important. To attain a high response rate, a follow-up process should be implemented as an integral part of the customer satisfaction survey. An individual trained in phone interview techniques can call customers who have not responded. This is done with the approval of the relationship manager for those clients. A follow-up process can provide valuable insight on the reasons for a poor response rate.

An effective communication mechanism must be in place for reporting results back to the organization for appropriate action. Managers need to understand what conclusions can and cannot be drawn from the data received. There is a tendency to formulate conclusions 

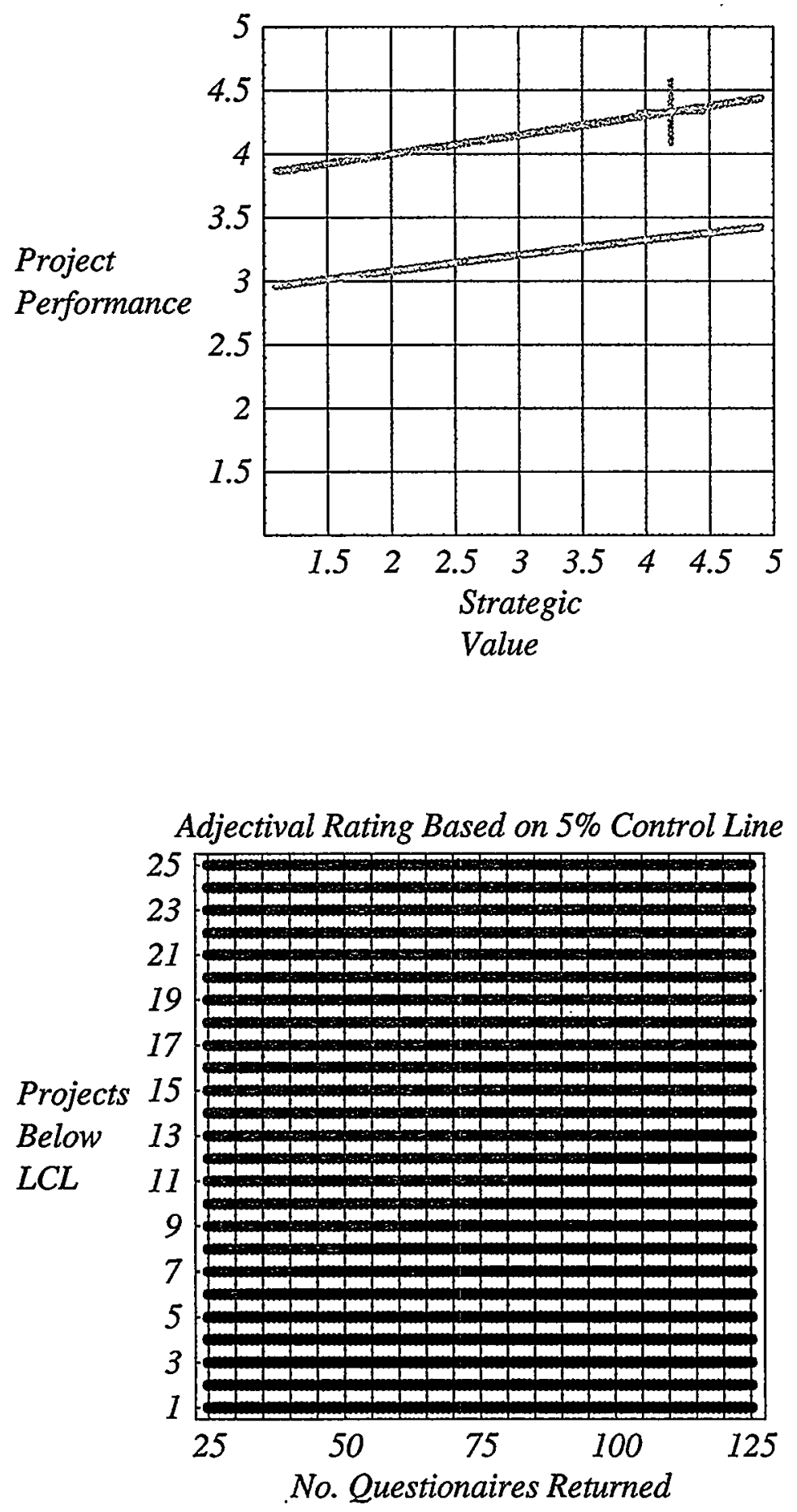

Figure 4: Gold Standard Model and Adjectival Rating Regions for a $5^{\text {th }}$ percentile Testing Rule. 
without a sufficient quantity or quality of data. A comprehensive electronic web page is a good mechanism for information distribution.

It is important to resist the temptation to begin a survey process without utilizing statistical survey design. Without a proper statistical design, the true customer satisfaction baseline cannot be adequately determined and organizational expectations can be poorly defined. It becomes very difficult to move toward statistical design incrementally because the organization then fears a large fluctuation in the baseline that will be unexplained. There is then reluctance in the organization to admit that they did not begin with a statistical survey design in the first place.

\section{Acknowledgments}

The authors acknowledge the support of Jeffrey W. Smith (ORNL Laboratory Operations Director), Dr. John LaFemina (PNNL Quality Director) and Brent Pulsipher (PNNL Statistics Resources Manager). The authors assume full responsibility for any errors or omissions.

\section{References}

[Hayes, 1998] Hayes, R. E. (1998). Measuring Customer Satisfaction: Survey Design, Use and Statistical Analysis Methods. ASQC Quality Press, Milwaukee, WI.

[Kessler, 1995] Kessler, S. (1995). Total Quality Service: A Simplified Approach to Using the Baldwin Award Criteria. ASQC Quality Press, Milwaukee, WI.

[Kessler, 1996] Kessler, S. (1996). Measuring and Managing Customer Satisfaction. ASQC Quality Press, Milwaukee, WI.

[Scheaffer et al., 1990] Scheaffer, R. L., Mendenhall, W., and Ott, L. (1990). Elementary . Survey Sampling. Duxbury Press, Belmont, CA.

[Vavra, 1996] Vavra, T. G. (1996). Improving Your Measurement of Customer Satisfaction. ASQC Quality Press, Milwaukee, WI. 


\section{A Model Development and Statistical Details}

\section{A.1 The Composite Scores Model}

Let $X$ denote the Strategic Value composite, and $Y$ denote the Project Performance composite from a questionnaire. Because the composites are averages of Likert scores, $\mathcal{L} \leq X \leq \mathcal{U}$ and $\mathcal{L} \leq Y \leq \mathcal{U}$. The composite scores model is derived with the generalized $\beta$ distribution. With the functions $a(x)$ and $b(x)$ defined so that $E(Y \mid X=x)=\lambda+\rho x$ and $\operatorname{Var}(Y \mid X=x)=\sigma^{2}$, the model is defined by the probability density functions

$$
\begin{aligned}
& f_{X}(x)=\frac{\Gamma(\alpha+\beta)}{\Gamma(\alpha) \Gamma(\beta)} \frac{(x-\mathcal{L})^{\alpha-1}(\mathcal{U}-x)^{\beta-1}}{(\mathcal{U}-\mathcal{L})^{\alpha+\beta-1}} \quad \mathcal{L} \leq x \leq \mathcal{U} ; \alpha>0 ; \beta>0 \\
& f_{X}(x)=0 \text { Otherwise }
\end{aligned}
$$

$$
f_{Y \mid X}(y)=\frac{\Gamma(a(x)+b(x))}{\Gamma(a(x)) \Gamma(b(x))} \frac{(y-\mathcal{L})^{a(x)-1}(\mathcal{U}-y)^{b(x)-1}}{(\mathcal{U}-\mathcal{L})^{a(x)+b(x)-1}} \cdot \mathcal{L} \leq y \leq \mathcal{U} ; a(x)>0 ; b(x)>0
$$

$f_{Y \mid X}(y)=0 \quad$ Otherwise

subject to

$$
\begin{gathered}
E(Y \mid X)=\lambda+\rho x=(\mathcal{U}-\mathcal{L}) \frac{a(x)}{a(x)+b(x)}+\mathcal{L}, \\
\operatorname{Var}(Y \mid X)=\sigma^{2}=(\mathcal{U}-\mathcal{L})^{2} \frac{a(x) b(x)}{(a(x)+b(x))^{2}(a(x)+b(x)+1)} .
\end{gathered}
$$

The values of $\mathcal{L}$ and $\mathcal{U}$ are assumed known. For example, $\mathcal{L}=1$ and $\mathcal{U}=5$ for a questionnaire based on a 5 -point Likert scale. Direct algebraic manipulation gives

$$
\begin{aligned}
& a(x)=\frac{(\lambda+\rho x-\mathcal{L})\left((\lambda+\rho x-\mathcal{L})(\mathcal{U}-\lambda-\rho x)-\sigma^{2}\right)}{(\mathcal{U}-\mathcal{L}) \sigma^{2}} \\
& b(x)=\frac{(\mathcal{U}-\lambda-\rho x)\left((\mathcal{U}-\lambda-\rho x)(\lambda+\rho x-\mathcal{L})-\sigma^{2}\right)}{(\mathcal{U}-\mathcal{L}) \sigma^{2}} .
\end{aligned}
$$

Constraints that ensure $a(x)>0$ and $b(x)>0$ are

$$
\begin{aligned}
& \mathcal{L} \leq \lambda \leq \mathcal{U} \\
& \frac{\mathcal{L}-\lambda}{\mathcal{U}} \leq \rho \leq \frac{\mathcal{U}-\lambda}{\mathcal{U}} \\
& 0<\sigma<\frac{\mathcal{U}-\mathcal{L}}{2} .
\end{aligned}
$$




\section{A.2 Establishing a Gold Standard}

The method of selecting $\alpha_{0}, \beta_{0}, \lambda_{0}, \rho_{0}, \sigma_{0}$ is developed with an example. Suppose the laboratory expectation is to have the average Strategic Value of all projects equal to $\mu=4$. Also, most of the projects should have a Strategic Value in the interval 3 to 5, which gives the range $\mathcal{R}=5-3=2$. If the mean and standard deviation of the Strategic Value model are written in terms of $\mathcal{L}, \mathcal{U}, \mathcal{R}$, the Strategic Value laboratory standard is

$$
\begin{aligned}
\alpha_{0} & =\frac{(\mu-\mathcal{L})\left((\mu-\mathcal{L})(\mathcal{U}-\mu)-(\mathcal{R} / 4)^{2}\right)}{(\mathcal{U}-\mathcal{L})(\mathcal{R} / 4)^{2}} \\
\beta_{0} & =\frac{(\mathcal{U}-\mu)\left((\mathcal{U}-\mu)(\mu-\mathcal{L})-(\mathcal{R} / 4)^{2}\right)}{(\mathcal{U}-\mathcal{L})(\mathcal{R} / 4)^{2}} .
\end{aligned}
$$

For example,

$$
\begin{aligned}
& \alpha_{0}=\frac{(4-1)\left((4-1)(5-4)-(2 / 4)^{2}\right)}{(5-1)(2 / 4)^{2}}=8.25 \\
& \beta_{0}=\frac{(5-4)\left((5-4)(4-1)-(2 / 4)^{2}\right)}{(5-1)(2 / 4)^{2}}=2.75
\end{aligned}
$$

To identify $\lambda_{0}, \rho_{0}$, simply pick two values of Strategic Value, say $x^{\prime}=2$ and $x^{\prime \prime}=4$. Then specify average Project Performance at these levels. For example, set the Project Performance expectations of $y^{\prime}=3$ and $y^{\prime \prime}=4$. Solving this system of equations gives.

$$
\begin{aligned}
& \rho_{0}=\frac{y^{\prime \prime}-y^{\prime}}{x^{\prime \prime}-x^{\prime}} \\
& \lambda_{0}=\frac{y^{\prime} x^{\prime \prime}-y^{\prime \prime} x^{\prime}}{x^{\prime \prime}-x^{\prime}},
\end{aligned}
$$

and upon substitution, $\lambda_{0}=2, \rho_{0}=0.5$. These values satisfy the constraint Equations 4 . For $\sigma_{0}, 0<\sigma_{0}<(\mathcal{U}-\mathcal{L}) / 2$ is required - an initial value of $\sigma_{0}=(\mathcal{U}-\mathcal{L}) / 8$ should be used. As laboratory performance is better understood, the value of $\sigma_{0}$ may be mildly reduced.

\section{A.3 Establishing a Standard for Agreement between Customer and PNNL Business Unit Manager Assessments of Strategic. Value}

Let $X=V_{M}$ denote the laboratory Strategic Value composite, and $Y=V_{C}$ denote the customer Strategic Value composite. The Strategic Value agreement model is derived with the generalized $\beta$ distribution. With the functions $a(x)$ and $b(x)$ defined so that $E(Y \mid X=x)=\alpha_{0}+\alpha_{1} x$ and $\operatorname{Var}(Y \mid X=x)=\tau^{2}$, the model is defined by the 
probability density function

$$
f_{Y \mid X}(y)=\frac{\Gamma(a(x)+b(x))}{\Gamma(a(x)) \Gamma(b(x))} \frac{(y-\mathcal{L})^{a(x)-1}(\mathcal{U}-y)^{b(x)-1}}{(\mathcal{U}-\mathcal{L})^{a(x)+b(x)-1}} \quad \mathcal{L} \leq y \leq \mathcal{U} ; a(x)>0 ; b(x)>0
$$

$f_{Y \mid X}(y)=0 \quad$ Otherwise

subject to

$$
\begin{gathered}
E(Y \mid X=x)=\alpha_{0}+\alpha_{1} x=(\mathcal{U}-\mathcal{L}) \frac{a(x)}{a(x)+b(x)}+\mathcal{L} \\
\operatorname{Var}(Y \mid X)=\tau^{2}=(\mathcal{U}-\mathcal{L})^{2} \frac{a(x) b(x)}{(a(x)+b(x))^{2}(a(x)+b(x)+1)}
\end{gathered}
$$

Direct algebraic manipulation gives

$$
\begin{aligned}
& a(x)=\frac{\left(\alpha_{0}+\alpha_{1} x-\mathcal{L}\right)\left(\left(\alpha_{0}+\alpha_{1} x-\mathcal{L}\right)\left(\mathcal{U}-\alpha_{0}-\alpha_{1} x\right)-\tau^{2}\right)}{(\mathcal{U}-\mathcal{L}) \tau^{2}} \\
& b(x)=\frac{\left(\mathcal{U}-\alpha_{0}-\alpha_{1} x\right)\left(\left(\mathcal{U}-\alpha_{0}-\alpha_{1} x\right)\left(\alpha_{0}+\alpha_{1} x-\mathcal{L}\right)-\tau^{2}\right)}{(\mathcal{U}-\mathcal{L}) \tau^{2}} .
\end{aligned}
$$

Constraints that ensure $a(x)>0$ and $b(x)>0$ are

$$
\begin{aligned}
& \mathcal{L} \leq \alpha_{0} \leq \mathcal{U} \\
& \frac{\mathcal{L}-\alpha_{0}}{\mathcal{U}} \leq \alpha_{1} \leq \frac{\mathcal{U}-\alpha_{0}}{\mathcal{U}} \\
& 0<\tau<\frac{\mathcal{U}-\mathcal{L}}{2} .
\end{aligned}
$$

This derivation is precisely the same as the composite score derivation in Section A.1. The $\beta$ distribution correctly describes the properties of the Strategic Value composites because of its ability to represent skewness. For a value of $V_{M}$ near $\mathcal{U}$, values of $V_{C}$ may by also be near $\mathcal{U}$; however, the $V_{C}$ values will realistically be skewed toward $\mathcal{L}$. Also, for a value of $V_{M}$ near $\mathcal{L}$, values of $V_{C}$ may by also be near $\mathcal{L}$; however, the $V_{C}$ values will be skewed toward $\mathcal{U}$. This observation imposes further constraints on the agreement model (Equation $8)$ in order to establish a realistic definition of what is meant by agreement. One method to achieve a realistic model is to require $E(Y \mid X=x)+\tau<\mathcal{U}$ and $E(Y \mid X=x)-\tau>\mathcal{L}$. These constraints imply that

$$
\frac{\mathcal{L}+\tau-\alpha_{0}}{\mathcal{L}}<\alpha_{1}<\frac{\mathcal{U}-\tau-\alpha_{0}}{\mathcal{U}} .
$$

The requirement that

$$
\frac{\mathcal{L}+\tau-\alpha_{0}}{\mathcal{L}}<\frac{\mathcal{U}-\tau-\alpha_{0}}{\mathcal{U}}
$$


implies

$$
\alpha_{0}>\frac{\tau(\mathcal{U}+\mathcal{L})}{(\mathcal{U}-\mathcal{L})}
$$

Equations 11 and 12 will provide the constraints that will result in a Strategic Value agreement model that can realistically represent composite score data. Intuitively, these constraints state that $E(Y \mid X=\mathcal{U})=\mathcal{U}$ is unrealistic because this implies an agreement model with no variability - all the data would need to be tightly packed around the point $(\mathcal{U}, \mathcal{U})$. Equations 11 and 12 define agreement in the presence of uncertainty. Under these constraints, upper and lower boundary lines can be computed that define a (1-p)\% probability region. Data that fall interior to this region would be concordant data. An example is given in Figure 3.

\section{A.4 Assessing Laboratory Expectations}

Equations 1 and 2 define a gold standard model, and Equation 2 effectively defines a lower control limit (LCL) for project performance. For each given value of $X=x$, the $p$ th percentile of $Y$ can be computed. This $p$ th percentile line is a lower control limit that objectively identifies projects that are inconsistent with the defined gold standard. To avoid problems with small values of $p$, (observing very unlikely events) a value of $p$ no lower than 5 should be used (a $5^{\text {th }}$ percentile line). Now, define two probability events:

$$
\begin{aligned}
& \mathrm{E} \equiv A \text { project has composite scores below the } L C L \\
& \mathrm{R} \equiv A \text { customer satisfaction survey is returned for analysis. }
\end{aligned}
$$

With a direct application of basic probability,

$$
\begin{aligned}
& P(\mathrm{E})=P(\mathrm{E} \cap \mathrm{R})+P(\mathrm{E} \cap \overline{\mathrm{R}}) \\
& \quad=P(\mathrm{R}) P(\mathrm{E} \mid \mathrm{R})+P(\overline{\mathrm{R}}) P(\mathrm{E} \mid \overline{\mathrm{R}}) .
\end{aligned}
$$

The primary assumption to this analysis method is that

$$
P(\mathrm{E} \mid \mathrm{R})=P(\mathrm{E} \mid \overline{\mathrm{R}})
$$

Thus, the analysis assumes that returned surveys are a good representation of the true laboratory performance for all projects in the laboratory portfolio. Also, each project in the sample is independently selected for inclusion in the survey. The logic of the analysis is to assume the gold standard model truly represents the performance of the laboratory, and then see if the survey data are in contradiction. If the gold standard model is the correct representation of laboratory performance, approximately $p \%$ of the random sample will be below the LCL by chance alone. For the survey data to contradict the gold standard model, much more than $p \%$ of the random sample needs to be below the LCL. With $n^{\prime}$ returned surveys, the number $M$ of composite scores below the LCL follows a binomial 
distribution with parameters $n^{\prime}$ and $p\left(M \sim \operatorname{binomial}\left(n^{\prime}, p\right)\right)$. If $m$ of the $n^{\prime}$ surveys have composite scores below the LCL, then compute $\pi=P(M \geq m)$. The adjectival ratings can be assigned with the rules

$$
\begin{cases}\pi<0.001 & \text { Marginal/Poor } \\ 0.001 \leq \pi<0.008 & \text { Good } \\ 0.008 \leq \pi<0.04 & \text { Excellent } \\ 0.04<\pi & \text { Outstanding. }\end{cases}
$$




\section{B PNNL Customer Satisfaction Questionnaire}




\section{Pacific Northwest National Laboratory \\ Customer Feedback Survey}

\section{DNN WNORNATONONIY \\ Product Itine:\#: \\ Project Mgr:}

\section{Project Title:}

Customer Contact

Date: $-$

Return Completed Survey by: August 21, 1998

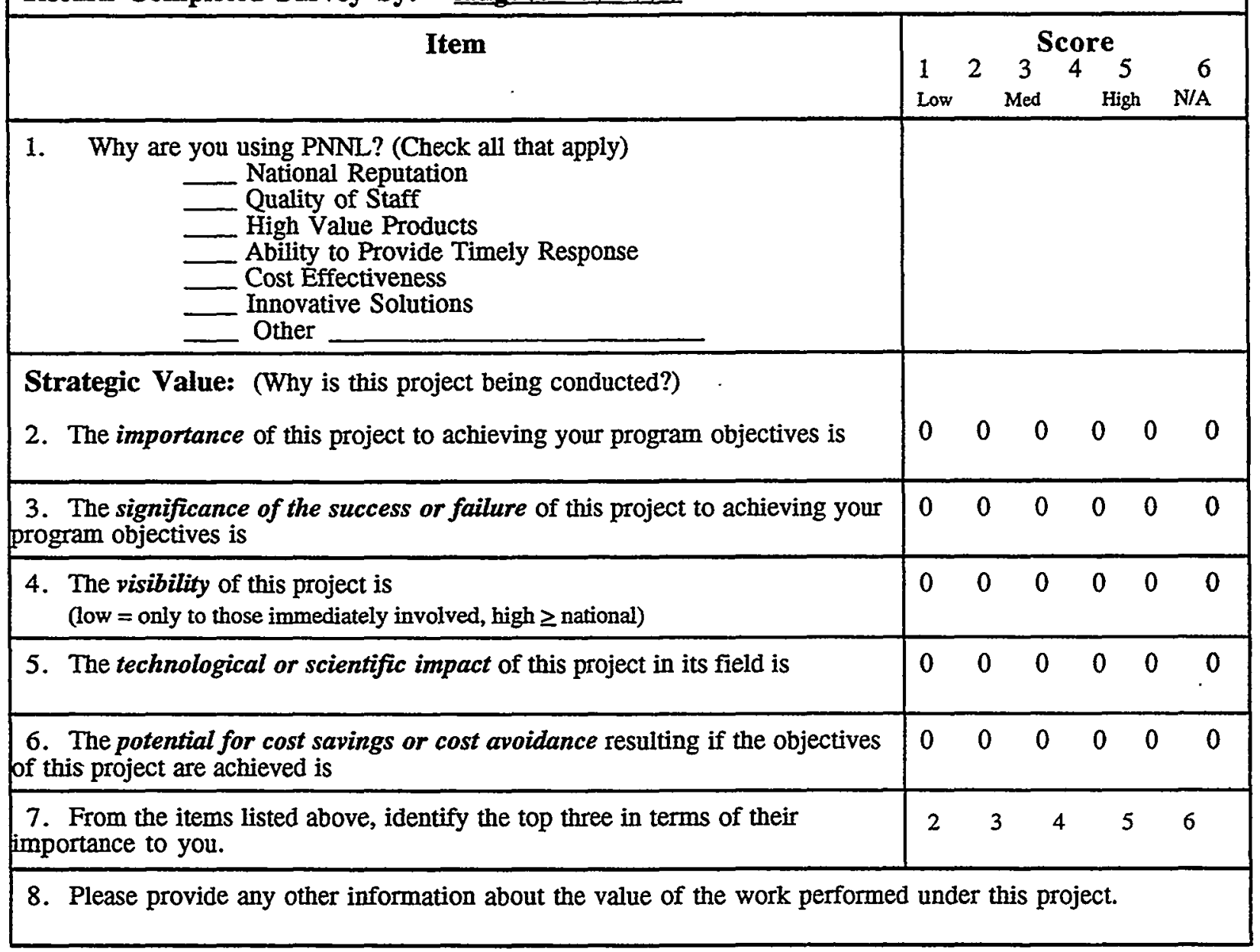




\begin{tabular}{|c|c|c|c|c|c|c|}
\hline $\begin{array}{l}\text { Project Performance: Rate Pacific Northwest National Laboratory's } \\
\text { ability to }\end{array}$ & $\begin{array}{l}1 \\
\text { Lor }\end{array}$ & & & ore & & $\begin{array}{ccc}6 \\
\mathrm{NA} \\
3\end{array}$ \\
\hline 9. Understand what the project needs to achieve and how to achieve it & 0 & 0 & 0 & 0 & 0 & \\
\hline $\begin{array}{l}\text { 10. Integrate technologies, methodologies, or disciplines that enhance } \\
\text { project performance }\end{array}$ & 0 & 0 & 0 & 0 & 0 & \\
\hline $\begin{array}{l}\text { 11. Deploy, unique skills and capabilities (e.g., key staff and/or project } \\
\text { manager, facilities, and/or equipment) }\end{array}$ & 0 & 0 & 0 & 0 & 0 & \\
\hline 12. Deliver products/services on time & 0 & 0 & 0 & 0 & 0 & $\angle$ \\
\hline 13. Deliver cost-effective products/services & 0 & 0 & 0 & 0 & 0 & \\
\hline $\begin{array}{l}\text { 14. Work effectively with you, being flexible and responsive to your needs } \\
\text { and expectations }\end{array}$ & 0 & 0 & 0 & 0 & 0 & \\
\hline 15. Deliver products that meet your expectations for quality & 0 & 0 & 0 & 0 & 0 & \\
\hline $\begin{array}{l}\text { 16. Provide new technologies or technical approaches that can be extended } \\
\text { or further developed }\end{array}$ & 0 & 0 & 0 & 0 & 0 & 0 \\
\hline $\begin{array}{l}\text { 17. Bring together industrial partners with a strong track record in } \\
\text { commercialization of new technologies or technical approaches }\end{array}$ & 0 & 0 & 0 & 0 & 0 & 0 \\
\hline
\end{tabular}

18. From the items listed above, identify the top four items in terms of their importance to you

$$
\begin{array}{lllllllll}
9 & 10 & 11 & 12 & 13 & 14 & 15 & 16 & 17
\end{array}
$$

19. How do we compare with our competitors?

20. How can we serve you better?

21. Please provide any other information you would like to share about our products/services (e.g., how do you rank the intangible benefits of our work, such as objectivity, trust, commitment; how can we improve?). 
PNNL-13057

\section{Distribution}

No. of

Copies

OFFSITE

L.E. Bradford

Battelle Columbus Office

505 King Avenue

Columbus, OH 43201-2693

R.M. Ecker

Battelle Marine Science Laboratory 1529 W. Sequim Bay Road

Sequim, WA 98392

J.W. Smith

Oak Ridge National Laboratory

1 Bethel Valley Road

Building 2001, MS-6055

Oak Ridge, TN 37831-6055

\section{ONSITE}

DOE-RL

J.K. Erickson

P.W. Kruger
No. of

Copies

35 Pacific Northwest National

Laboratory

J.F. Adams

K8-15

D.N. Anderson (5)

$\mathrm{K} 5-12$

O.P. Bredt

K9-44

R. Carlomusto (5)

$\mathrm{K} 1-30$

S.R. Cassidy

K9-72

G.K. Gerke . K6-48

D.P. Keeser

$\mathrm{K} 5-02$

K.J. Kuhl-Klinger

$\mathrm{K} 1-33$

J.P. LaFemina

K1-40

P.X. Linnen

$\mathrm{K} 1-43$

E.W. Pearson K1-50

L.J. Powell . K1-46

B.A. Pulsipher

K5-12

A. Roberts

$\mathrm{K} 1-46$

R.M. Schwenk

$\mathrm{K} 9-78$

M.L. Sours (5)

K1-30

Information Release Office (7)K1-06

Distr.1 